\title{
VET workers' problem-solving skills in technology-rich environments: European approach
}

\author{
Raija Hämäläinen* \\ University of Jyväskylä, \\ Finnish Institute for Educational Research, \\ P.O.Box 35, 40014 Jyväskylä, Finland \\ E-mail: raija.h.hamalainen@jyu.fi \\ Sebastiano Cincinnato \\ Ghent University \\ Department of Educational Studies \\ Henri Dunantlaan 2, B-9000 Ghent, Belgium \\ E-mail: Sebastiano.Cincinnato@UGent.be
}

\author{
Antero Malin \\ University of Jyväskylä, \\ Finnish Institute for Educational Research, \\ P.O.Box 35, 40014 Jyväskylä, Finland \\ E-mail: antero.malin@jyu.fi \\ Bram De Wever \\ Ghent University \\ Department of Educational Studies \\ Henri Dunantlaan 2, B-9000 Ghent, Belgium \\ E-mail: Bram.DeWever@UGent.be \\ * Corresponding author
}

Received: 11 June 2014; Accepted: 12 August 2014; Published online: 31 August 2014

\begin{abstract}
The European workplace is challenging VET adults' problem-solving skills in technology-rich environments (TREs). So far, no international large-scale assessment data has been available for VET. The PIAAC data comprise the most comprehensive source of information on adults' skills to date. The present study $(\mathrm{N}=50369)$ focuses on gaining insight into the problem-solving skills in TREs of adults with a VET background. When examining the similarities and differences in VET adults' problem-solving skills in TREs across 11 European countries, two main trends can be observed. First, our results show that only a minority of VET adults perform at a high level. Second, there seems to be substantial variation between countries with respect to the proportion of VET adults that can be identified as "at-risk" or "weak" performers. For the future, our findings indicate the variations that can be used as a starting point to identify beneficial VET approaches.
\end{abstract}


Keywords: Adults with vocational education and training, Large-scale assessment, PIAAC, Technology-rich environments, Problem-solving, Workplace skills.

\section{Bibliographical notes:}

Adjunct Professor (Ph.D) Raija Hämäläinen works at the Finnish Institute for Educational Research, University of Jyväskylä. She has designed long-term research project that focuses on investigating new learning spaces for the future vocational education. Her research interests focus on technology-enhanced learning (TEL) at workplace contexts.

Sebastiano Cincinnato works as a researcher at the Department of Educational studies at Ghent University, Belgium. He was one of the researchers for the OECD Programme for the International Assessment of Adult Competencies (PIAAC) in Belgium. His research interests focus on the learning divide in adult education.

Ph.D Antero Malin is the professor in the field of quantitative methodology in educational research and the head of the Quantitative Methods and Data Management Unit in the Finnish Institute for Educational Research, University of Jyväskylä. Recently, Malin has been the National Project Manager of the OECD Programme for the International Assessment of Adult Competencies (PIAAC).

Bram De Wever (Ph.D) works at the Department of Educational Studies. He got a tenure track position on Technology Enhanced Learning and Instruction in 2010. His research interests are related to computer-supported collaborative learning in (higher) education. He is also teaching a course on adult education at Ghent University.

Acknowledgments: This research was supported by the Academy of Finland (Project n:o 258659). 


\section{Introduction}

The European workplace is going through a radical process of structural change, from mass-production technology to more flexible production methods. For adults with vocational education and training (VET), this structural change often means changes in their job descriptions (as routine tasks are taken over by technologies, Goos, 2013). As a direct result, many of today's workplaces require creative problem-solving instead of in-routine activities in a variety of technology-rich settings. Therefore, the ability to work and solve problems in technology-rich environments (TREs) plays an increasingly important role (Frey and Osborne, 2013; Goos, 2013). Related to this change, adults' problem-solving skills (or the lack thereof) may have short-term influence on how well workers are able to manage their work tasks and long-term influence on European welfare and competitiveness. As a direct result of this advancement, problem-solving in Europe's TRE is one of the most important skills for future working life (Goos, 2013). In line with these emerging requirements, it is generally agreed that there is a need to develop adults' skills and abilities to better meet the changing needs of the European workplace in terms of problem-solving in TRE, for example through formal education (Billett, 2008; Teichler, 2007; Fuller and Unwin, 2004) and lifelong (Loveder, 2011) and workplace learning (Billett, 2008; Tynjälä, 2013).

Currently, there is an emerging need for a greater understanding of the relationship between VET adults' problem-solving skills in a TRE and their educational needs in these same realms at the European level. According to Lawn (2013), at best, it may be possible to benefit from the knowledge gathered from large-scale assessments in providing indicators of the skills of the adult population. The aim is that, when adults' skills are analysed together with educational systems, educational approaches are better able to meet emerging societal needs. Recently, results of the Programme for the International Assessment of Adult Competencies (PIAAC) - the most comprehensive study of adult skills ever undertaken, led by the Organisation for Economic Co-operation and Development (OECD) - showed that problem-solving skills in TREs vary among the European countries (OECD, 2013a). In general, Nordic countries, such as Finland, had overall high proficiency levels in problem solving in TREs. However, a recent analysis of the PIAAC data (Hämäläinen, De Wever, Malin and Cincinnato, 2014) highlighted the critical issue that, despite Finns' high proficiency in general for problem-solving in TREs, the majority of adults with VET have weak skills or lack skills needed to solve problems in TREs. As a direct result, a crucial question for VET development involves investigating if the same trend holds true in other parts of Europe. Thus, we need to investigate what the level and distribution of problem-solving skills in TREs for adults with VET is in Europe and how well adults' vocational skills and professional expertise match the changing needs of European society.

As a starting point for investigating VET adults' skills and abilities, we have to consider that, in general, VET education approaches vary between European countries (for a detailed description, see Eurydice Highlights 2012/2013; OECD, 2009), and this may have an influence on adults' problem-solving skills in TREs. Specifically, VET has traditionally been based on either school- or work-based approaches (European Commission, 2013). In work-based approaches (applied, following the Eurydice Highlights 2012/2013, for example, in Germany, Austria and Switzerland) learning is intertwined with authentic work contexts, and learners spend a minimal amount of their time in a school setting. Alternatively, in school- 
based approaches (such as in France and Scandinavian countries, including Norway and Finland), learning more often takes place in traditional school settings. However, despite the differences in the approach of where vocational learning takes place, both approaches face the same challenge of structural changes in Europe's workplace. For these reasons, critical discussions are currently underway about whether the new needs of the structural change (e.g. skills and abilities of creative problem-solving in TREs) have reached our VET adults in a satisfactory way. Furthermore, it is important to find out how different European VET education approaches are associated with VET adults' problem-solving skills in TREs.

\section{Aims}

Europe's workplace calls for a new understanding of VET adults' problem-solving skills in TREs. So far, no international large-scale assessment data has been available for VET (cf. Programme for International Student Assessment (PISA) for 15-year student assessment and Assessment of Higher Education Learning Outcomes (AHELO) for higher education student assessment). Therefore, PIAAC data enables us to get new insight into the VET. Namely, this study aims to investigate VET adults' performance in problem-solving in TREs and its relation to educational approaches. Specifically, our aim was to identify:

- What is the level and distribution of problem-solving skills in TREs for adults with VET in Europe?

- How is the level and distribution of problem-solving skills in TREs for adults with VET related to adults with other educational backgrounds?

\section{Method}

In practice, PIAAC data and Eurostat classification of the VET approaches were used for this study. Firstly, we used the OECD PIAAC data to obtain knowledge on the VET adults' performance on problem-solving in TREs. The objective of the PIAAC was to determine whether adults' basic skills were at a level that made them ready to respond to the unpredictable needs of the future, which might involve rapid changes. Secondly, calculations of the European Centre for the Development of Vocational Training (Cedefop) based on Eurostat classification for upper secondary VET on work-based approaches (for detailed description see European Commission, 2013, p. 7) grounded our analysis.

\subsection{Data and analysis}

The PIAAC survey was conducted by an international consortium consisting of several research institutions and led by the Educational Testing Service (ETS, USA). Under the guidance of the consortium, each participating country implemented the survey (for a detailed description, see OECD, 2013b, chapters 10-13). The PIAAC survey contained, firstly, the background questionnaire including questions about skills used, and secondly, computer-based test results that captured the level of adults' problem-solving skills (OECD, 2013b). A total of 66,32216 - to 65 year olds were involved (average weighted response rate of $60 \%$, sample size of 113,744) in eleven European countries; 50,369 adults (males: $\mathrm{n}=24,812$, females: $\mathrm{n}=25,556$ ) took part in the test of problem-solving skills in TREs. 
In PIAAC, proficiency is regarded as a continuum of abilities involving the mastery of information-processing tasks of increasing complexity. The PIAAC test design was based on a variant of matrix sampling, which used different sets of items as well as multistage adaptive testing. In addition, it used a variety of assessment modes where each of the respondents completed a subset of items from the total item pool. Since calculating a one-point estimate of proficiency for each respondent might lead to severely biased estimates of population characteristics, PIAAC uses ten plausible values that are drawn from an a posteriori distribution. This is done by combining the item response theory (IRT) scaling of the cognitive items with a latent regression model using information from the background questionnaire. The PIAAC Technical Report (OECD, 2013b, chapter 17) provides further details of the scaling of cognitive data.

The results of problem-solving are represented on a 500-point scale, which was divided into four different proficiency levels. These levels are based on the skills and knowledge required to accomplish the tasks within each level. Level 1 ("weak performers") included scores from 241 to 290. Level 2 ("moderate performers") included scores from 291 to 340 and Level 3 ("strong performers") included scores equal to or higher than 341. Additionally, the participants who scored below Level 1 were defined as "at risk". Moreover, there is a "notclassified" group included in the sample. The reasons for this group not being classified are rather diverse (i.e. failed the ICT core test, no computer experience or opted out of the computer-based assessment, or fell out due to literacy-related nonresponse). As such, it is difficult to make proper statements about this group. Given the fact that there is no information at all with respect to their problem-solving proficiency level present in the database, we opted not to include them in our analyses, except for our first analyses presenting a general overview.

The statistical analyses were implemented by taking the survey design into account using weights. The mean of regressions over ten plausible values was calculated, using Jack-knife replication for variance estimation (for further details, see OECD, 2013b, chapters 14-15).

\subsection{Detecting the level of the problem-solving skills in TREs}

The aim of evaluating problem-solving in TREs was to assess how adults use technology in order to carry out a variety of complicated problem-solving tasks. The assessment framework as well as the tasks and the background questionnaire were designed by the international expert groups (OECD, 2012). In the PIAAC study, problem-solving in TREs is described below:

"Problem solving in technology-rich environments involves using digital technology, communication tools and networks to acquire and evaluate information, communicate with others and perform practical tasks. The first PIAAC problem solving survey will focus on the abilities to solve problems for personal, work and civic purposes by setting up appropriate goals and plans, accessing and making use of information through computers and computer networks". (OECD, 2012, p. 47)

In practice, during the test each participant solved tasks using various sources of information on a laptop computer. The computer environment offered several tools participants could use, such as an Internet browser and web pages, a computer-based reservation system, e-mail and word processing. To summarise, the main goal of the assessment was to explain to which extent adults use technology to solve today's problems both proficiently and efficiently (OECD, 
2012). In this study, the first step of the analysis was to calculate the level and distribution of participants' problem-solving skills.

\subsection{Investigating the differences in problem-solving skills between VET and other adults}

As the first phase of the investigation of problem-solving skills differences, VET and other adults were categorized based on their problem-solving scores. In the second phase, the similarities and differences with respect to the relation between participants' scores of the problem-solving test and educational background were discovered. Finally, a variety of adults with different educational backgrounds were compared. In our analysis, we used multinomial logit regression to estimate the likelihood of attaining an at-risk or weak proficiency level compared to a moderate or strong proficiency level (which are combined to act as the reference category). Additionally, in comparing the educational categories, adults with vocational education serve as the reference category, in order to compare VET adults with graduates from (at most) lower secondary education and graduates from (at least) upper secondary education.

\subsection{Examining the differences between the European countries applying school- or work-based approaches in VET}

To examine the differences between European countries we grounded our analysis on the orientation that European countries have taken in VET. Thus, we based our analysis on the Cedefop calculations of Eurostat data (see Table 1). In practice, we used the share of work-based practise as a starting point for dividing European countries that apply school- or work-based approaches in their educational systems. In this phase, we included all the countries listed on the Cedefop calculation ( 9 countries with low and 8 countries with high share of work-based learning; additionally for the rest of the European countries, no reliable data were available; for detailed information, see European Commission 2013; Eurydice Highlights 2012/2013; OECD, 2009). Next, we investigated all the countries in the Cedefop calculations that participate in the PIAAC study (13 countries) and selected those countries that had data on problem-solving in TREs (Spain and France were left out, as they did not participate in the problem-solving test of the PIAAC). Additionally, as the problem-solving proficiency scores are not available for the participants in the "not-classified" group, they were not included in statistical analyses. In practice, we included 6 countries with a low and 5 countries with a high share of work-based learning on our analyses (Table 1). Finally, to gain deeper insight into the problem-solving skills in TREs of European adults with a VET background, similarities and differences in VET adults' problem-solving skills across the European countries applying school- or work-based approaches in their education were investigated.

Table 1: Share of work-based learning in 11 countries

\begin{tabular}{|c|c|}
\hline \multicolumn{2}{|c|}{ Share of work-based learning } \\
\hline High & Low \\
\hline Austria, Slovak Republic, Czech & Belgium, Finland, Ireland, Netherland, \\
Republic, Denmark, Germany & Norway, Poland \\
\hline
\end{tabular}




\section{Results}

\subsection{The general overview of problem-solving skills in TREs in Europe}

In the following section we further shed light on the similarities and differences in VET adults' problem-solving skills across the European countries applying schoolor work-based approaches. Before that, we will firstly give an overview over VET adults' problem-solving skills, including the not-classified group, to give a general picture of the share of this group.

Figure 1 illustrates that among VET adults, there is a tendency to have a lack of or low problem-solving skills in all 11 countries. Specifically, only a small minority of VET adults score on the highest level (level 3) and 63\% or more of the adults with VET are below the moderate performance level (level 2). Additionally, in all of the countries more than $11 \%$ of the VET adults are at-risk performers in problem-solving. On average, one third of adults with VET are at Level 1. The pattern of distribution of adults at Level 1 is largely similar and close to the schooland work-based average in Austria, Czech Republic, Denmark and Finland.

Furthermore, a large share of VET adults belongs to the not-classified group, on average almost one third of VET adults both in the school- and work-based countries. The lowest share is in the Netherlands (8\%). Denmark and Norway $(16 \%)$ as well as Germany $(21 \%)$ are clearly below average. An interesting similarity between school- or work-based approaches can be noted: in both approaches there is one country with a high share of the VET adults belonging to the not-classified group (Slovak Republic and Poland, see Figure 1). These two countries clearly differ from the other countries in terms of having a large notclassified group, and because of that, fewer VET adults score the two highest levels of problem-solving skills (Figure 1). 


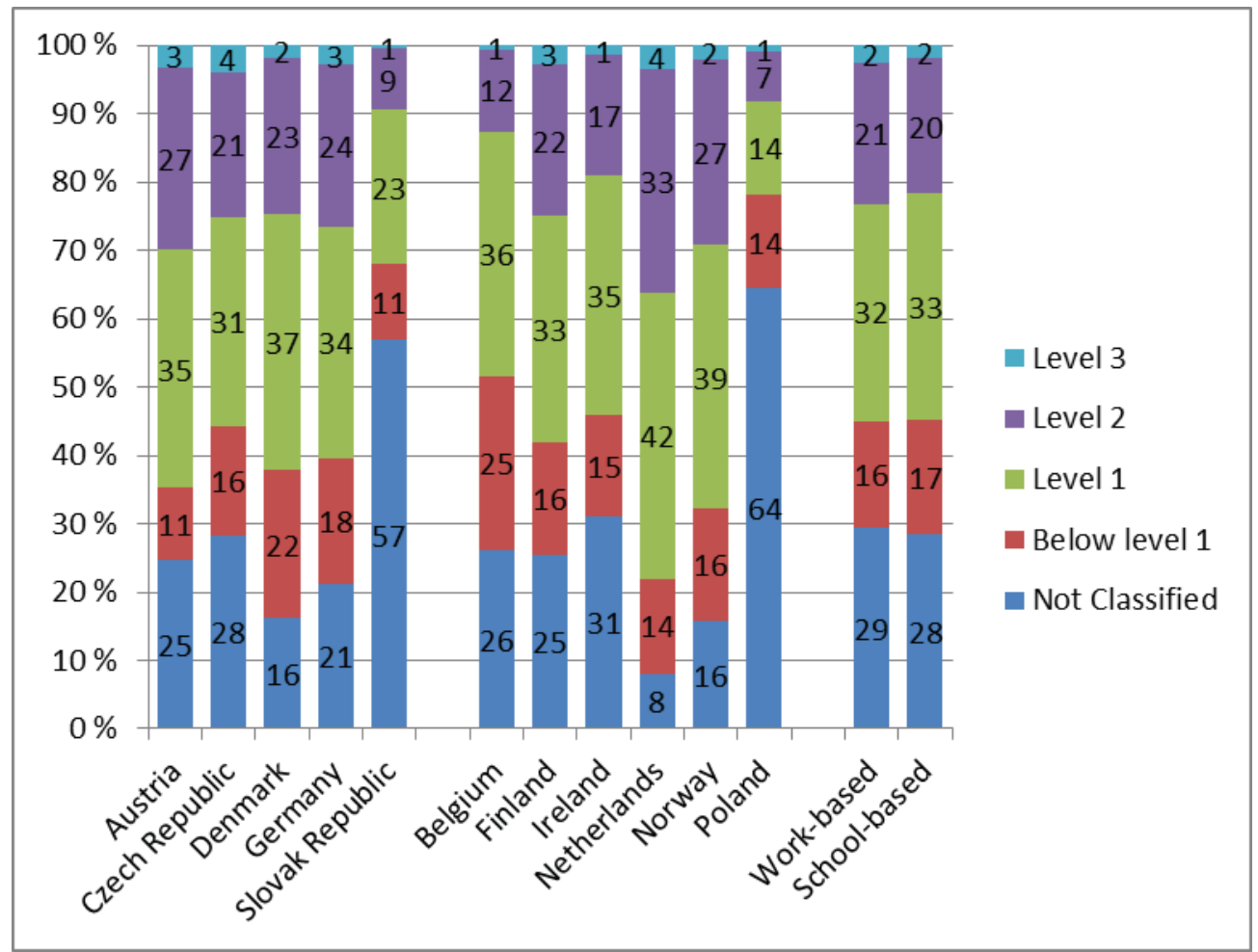

Note. Due to rounding, the percentages do not always add up to exactly 100 percent.

Figure 1: Percentage of VET adults scoring at each level of problem-solving skills by country

\subsection{The main differences between VET and other adults' problem-solving skills in TREs}

In all 11 countries, adults with VET perform lower on average than adults with other educational backgrounds. The average difference between work-based and school-based VET is very small (only 4 points, see Figure A1 in appendix). The difference between VET and non-VET adults' problem solving skills varies between countries, ranging from 8 points in Austria to 32 points in Belgium (see Figure A1 in appendix). Thus, there is no indication of an association between VET adults' problem-solving skills in TREs and education approaches applied in Europe. Instead, there is great variation in VET adults' average problem-solving skills in TREs across 11 European countries, irrespective of whether they are applying school- or work-based approaches. The lowest mean performance scores are found in Poland and Belgium (255 points) and the highest in Austria and the Netherlands (280 points).

When comparing VET adults to adults with at least upper secondary education, the latter strongly outperform the vocationally trained adults in all 11 countries (Figure 2). On average, graduates from upper secondary or higher score 26 points higher than VET graduates in work-based countries and 28 point higher in school-based countries. As the figures indicate, the difference between workbased and school-based countries is very small - although statistically significant $(p<0.05)$. However, there is variation between countries for both approaches. The difference is greatest in Belgium (42 points) and smallest in Ireland (17 points). 
Both of these countries apply the school-based approach. In the countries applying the work-based approach, the difference is greatest in Denmark (31 points) and smallest in Austria (18 points).

When comparing the VET group with adults with lower secondary education, adults with lower secondary education score higher in 7 out of 11 countries (Figure 2). In this instance, the difference between work- and school-based countries is more pronounced: while in work-based countries, adults with VET have a 4-pointlower average performance score compared to adults with lower secondary education $(\mathrm{p}<0.001)$, in the school-based countries there is no (statistically significant) difference in this respect $(p=0.554)$. The within-country variation is larger in school-based countries. The largest difference in favor of adults with lower secondary education is in Poland (25 points) and that in favor of VET adults is in Ireland (18 points). Among the work-based countries, the greatest difference in favor of adults with lower secondary education is in the Slovak Republic (17 points) and that in favor of VET adults is in Austria (12 points).

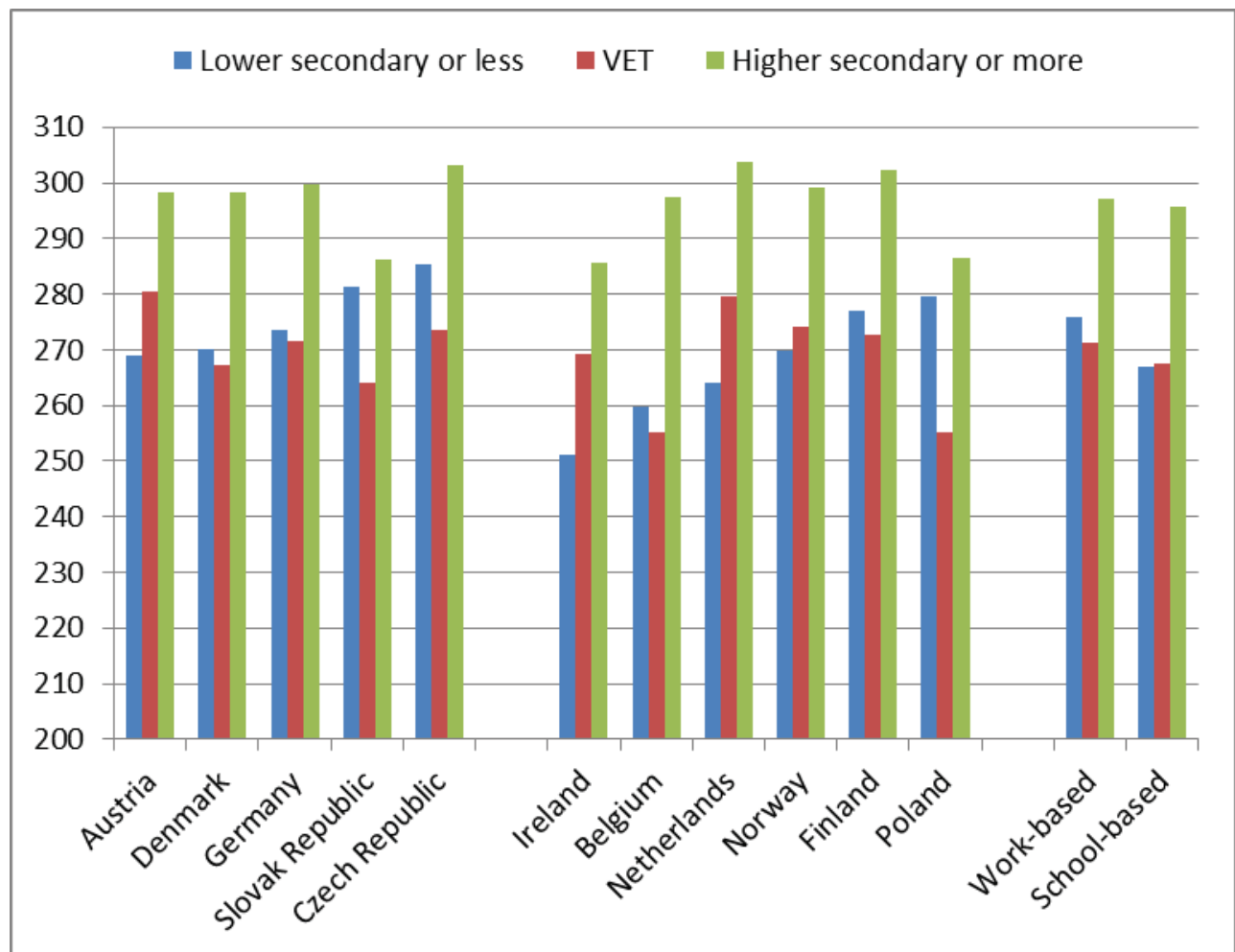

Note. Due to rounding, the percentages do not always add up to exactly 100 percent. An extended tabulation can be found in the appendix (Table A1).

Figure 2: Mean problem-solving scores by educational background for all countries

In Figures 3 and 4, we present the proportion of adults scoring at different proficiency levels of problem-solving in work- and school-based countries, excluding the not-classified group. When comparing VET adults to graduates from higher secondary school or higher, we observe that there is a clear difference in proportion among those scoring on lower (i.e. "at risk", and "weak") and higher 
levels (i.e. "moderate", and "strong"). In fact, in work-based countries, more than two thirds (68\%) of the VET adults perform on the lower levels compared to $42 \%$ of the graduates of higher secondary school. In the school-based countries, $71 \%$ of the VET adults perform on the lower levels compared to $43 \%$ of the graduates of higher secondary. However, the differences between countries are rather large, even when controlling for the VET-system approach. In work-based countries, we can observe that the proportion of low-performing VET adults varies between $60 \%$ (Austria) and 78\% (the Slovak Republic), whereas the proportion of lowperforming graduates from upper secondary varies between 36\% (the Czech Republic) and 55\% (the Slovak Republic). In school-based countries, Belgium (Flanders) has the highest proportion of VET-qualified low performers $(82 \%)$ and the Netherlands the lowest $(60 \%)$; the proportion of low-performing higher secondary graduates varies between 34\% (the Netherlands) and 54\% (Ireland).

Compared to lower secondary graduates (or less), VET adults show a slight tendency to have more adults performing on the low levels than the former. In work-based countries, we can observe that $61 \%$ of the lower secondary graduates have low levels of problem-solving skills (compared to 68\% of the VET adults), and in school-based countries, $68 \%$ of the lower secondary graduates perform at low proficiency levels (compared to $71 \%$ of VET adults). However, once again between-country differences are rather large, even when controlling for the VET system; in work-based countries the proportion of low achievers among lower secondary graduates varies between 52\% (the Czech Republic) and 69\% (Austria). 


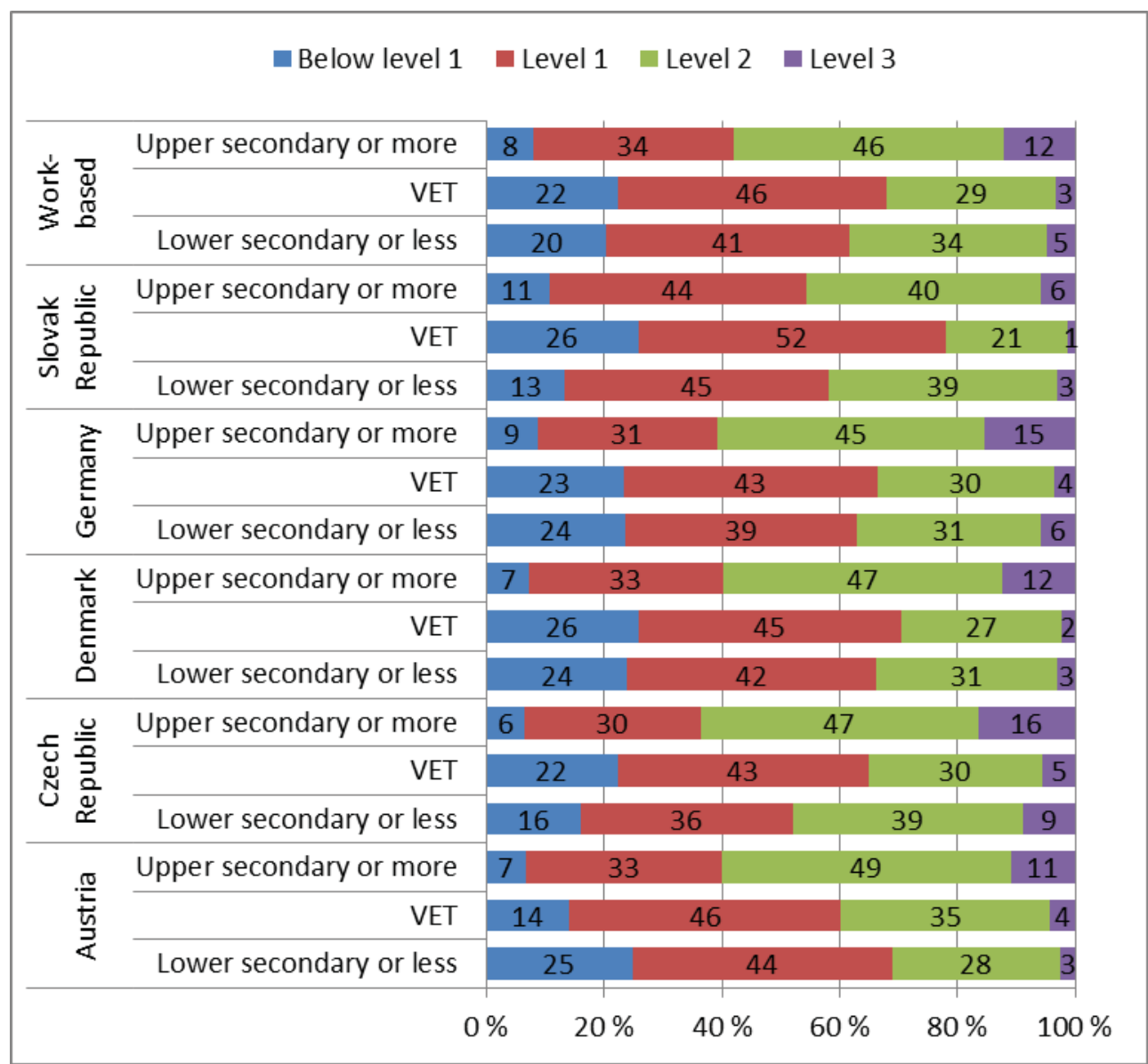

Note. Due to rounding, the percentages do not always add up to exactly 100 percent. An extended tabulation can be found in the appendix (Table A2).

Figure 3: Percentage of adults at each level of problem-solving skills in workbased countries 


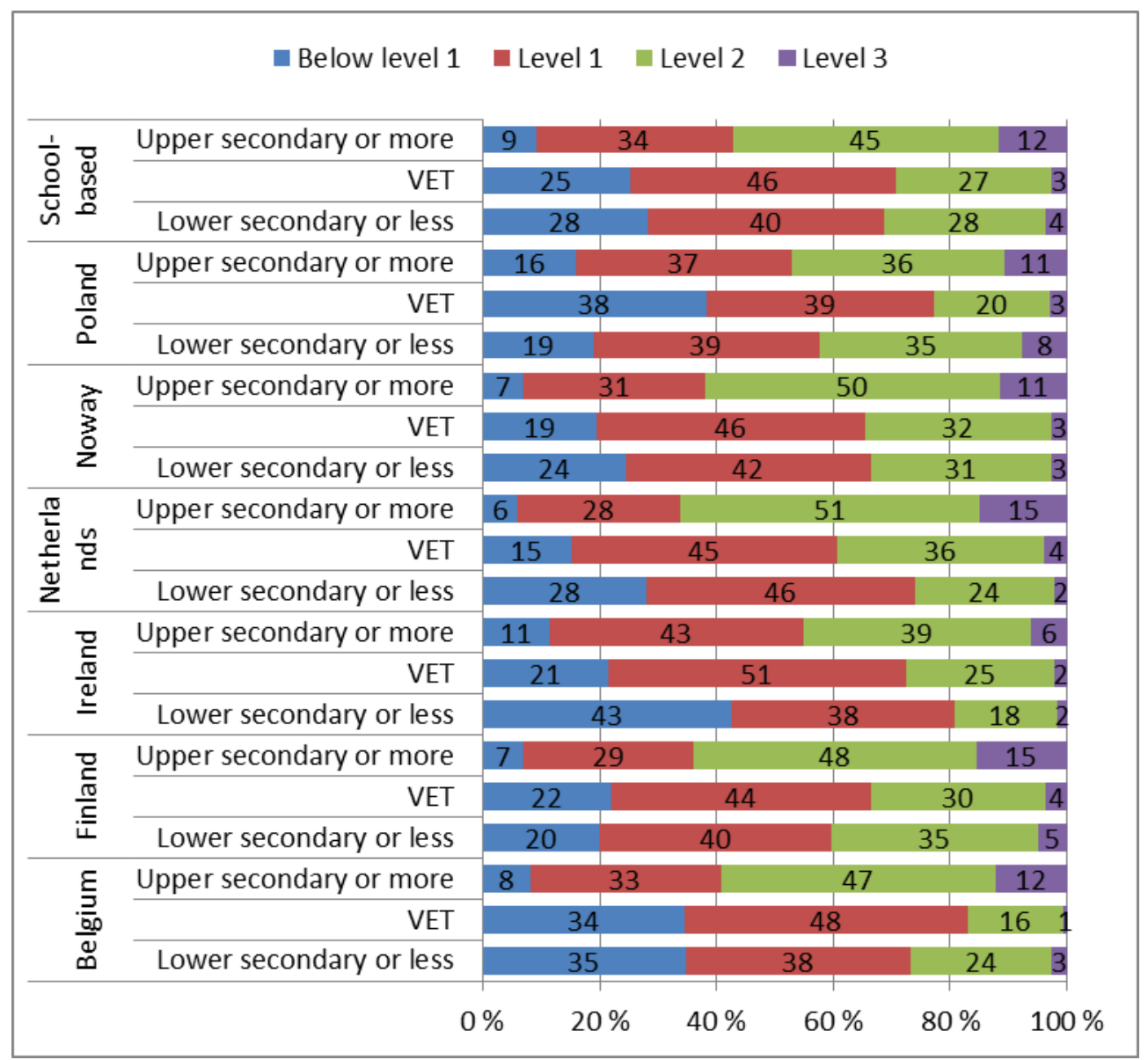

Note. Due to rounding, the percentages do not always add up to exactly 100 percent. An extended tabulation can be found in the appendix (Table A3).

Figure 4: Percentage of adults at each level of problem-solving skills in schoolbased countries

In order to examine the impact of educational background on problem-solving skills in work-based countries, in Table 2, we present the regression coefficients (and corresponding odds ratios) of the model estimating the likelihood of scoring at an "at risk" or "weak" problem-solving level compared to a "moderate and strong" proficiency level (i.e. the reference category). The figures clearly demonstrate that VET adults are more likely, compared to graduates from upper secondary school (or more), to be "at risk" or "weak" performers in problem-solving than "moderate or strong performers", independently from the country of origin. More precisely, VET adults are 3.2 (Austria) to 7.2 (Denmark) more likely to be "at-risk" performers, and 2.1 (Austria) to 2.8 (Denmark) more likely to be "weak" performers.

Interestingly, the between-country variation is larger when comparing the problem-solving skills of VET adults and graduates from lower secondary school (or less). In fact, with the exception of the Czech Republic, VET adults and lower secondary graduates are equally likely to be "weak" performers since the regression parameters are non-significant at a level of $\alpha=0.05$. In the Czech Republic, VET adults are 1.6 times more likely to be "weak" performers than 
lower secondary graduates. When estimating the likelihood of being an "at-risk" performer, the variation between countries is even more pronounced. More in particular, in the Czech Republic and the Slovak Republic, VET adults are respectively 1.9 and 3.7 times more likely to be "at-risk" performers. In Austria, on the contrary, lower secondary graduates are 2.3 times more likely than VET adults to be "at-risk" performers. In Denmark and Germany, the likelihoods are equal.

Table 2: Likelihood of problem-solving skills proficiency in TREs by educational background in work-based countries (parameter estimates with standard errors and odds ratios)

\begin{tabular}{|c|c|c|c|c|c|c|c|}
\hline & & \multicolumn{3}{|c|}{ At risk performers } & \multicolumn{3}{|c|}{ Weak performers } \\
\hline & & $\mathrm{b}$ & $\begin{array}{l}\text { Odds } \\
\text { ratio }\end{array}$ & $\begin{array}{l}\text { Inverse } \\
\text { odds } \\
\text { ratio }\end{array}$ & $\mathrm{b}$ & $\begin{array}{l}\text { Odds } \\
\text { ratio }\end{array}$ & $\begin{array}{l}\text { Inverse } \\
\text { odds } \\
\text { ratio }\end{array}$ \\
\hline \multirow[t]{3}{*}{ Austria } & Intercept & $\begin{array}{l}-1.04^{* * *} \\
(.085)\end{array}$ & & & $\begin{array}{l}0.15^{*} \\
(.067)\end{array}$ & & \\
\hline & Low Sec vs. VET & $\begin{array}{l}0.81^{* * *} \\
(.165)\end{array}$ & 2.26 & 0.44 & $\begin{array}{l}0.20 \\
(.149)\end{array}$ & 1.22 & 0.82 \\
\hline & Up Sec vs. VET & $\begin{array}{l}-1.16^{* * *} \\
(.200)\end{array}$ & 0.31 & 3.19 & $\begin{array}{l}-0.74^{* * *} \\
(.115)\end{array}$ & 0.48 & 2.10 \\
\hline \multirow[t]{3}{*}{$\begin{array}{l}\text { Czech } \\
\text { Republic }\end{array}$} & Intercept & $\begin{array}{l}-0.45^{* * *} \\
(.093)\end{array}$ & & & $\begin{array}{l}0.20^{*} \\
(.084)\end{array}$ & & \\
\hline & Low Sec vs. VET & $\begin{array}{l}-0.64^{* *} \\
(.226)\end{array}$ & 0.52 & 1.91 & $\begin{array}{l}-0.48^{*} \\
(.183)\end{array}$ & 0.62 & 1.61 \\
\hline & Up Sec vs. VET & $\begin{array}{l}-1.86^{* * *} \\
(.219)\end{array}$ & 0.16 & 6.43 & $\begin{array}{l}-0.94^{* * *} \\
(.158)\end{array}$ & 0.39 & 2.57 \\
\hline \multirow[t]{3}{*}{ Denmark } & Intercept & $\begin{array}{l}-0.13 \\
(.079)\end{array}$ & & & $\begin{array}{l}0.42^{* * *} \\
(.079)\end{array}$ & & \\
\hline & Low Sec vs. VET & $\begin{array}{l}-0.21 \\
(.128)\end{array}$ & 0.81 & 1.24 & $\begin{array}{l}-0.19 \\
(.117)\end{array}$ & 0.83 & 1.21 \\
\hline & Up Sec vs. VET & $\begin{array}{l}-1.97^{* * *} \\
(.125)\end{array}$ & 0.14 & 7.17 & $\begin{array}{l}-1.01^{* * *} \\
(.087)\end{array}$ & 0.36 & 2.75 \\
\hline \multirow[t]{3}{*}{ Germany } & Intercept & $\begin{array}{l}-0.37^{* * *} \\
(.085)\end{array}$ & & & $\begin{array}{l}0.24^{* * *} \\
(.067)\end{array}$ & & \\
\hline & Low Sec vs. VET & $\begin{array}{l}-0.08 \\
(.157)\end{array}$ & 0.92 & 1.09 & $\begin{array}{l}-0.19 \\
(.142)\end{array}$ & 0.83 & 1.21 \\
\hline & Up Sec vs. VET & $\begin{array}{l}-1.59^{* * *} \\
(.134)\end{array}$ & 0.20 & 4.90 & $\begin{array}{l}-0.93^{* * *} \\
(.101)\end{array}$ & 0.39 & 2.54 \\
\hline \multirow[t]{3}{*}{$\begin{array}{l}\text { Slovak } \\
\text { Republic }\end{array}$} & Intercept & $\begin{array}{l}0.16 \\
(.150)\end{array}$ & & & $\begin{array}{l}0.87^{*} \\
(.332)\end{array}$ & & \\
\hline & Low Sec vs. VET & $\begin{array}{l}-1.31^{* * *} \\
(.239)\end{array}$ & 0.27 & 3.71 & $\begin{array}{l}-0.81 \\
(.441)\end{array}$ & 0.45 & 2.24 \\
\hline & Up Sec vs. VET & $\begin{array}{l}-1.62^{* * *} \\
(.199)\end{array}$ & 0.20 & 5.03 & $\begin{array}{l}-0.92^{*} \\
(.368)\end{array}$ & 0.40 & 2.50 \\
\hline
\end{tabular}

Note. ${ }^{*} \mathrm{p}<0.05,{ }^{* *} \mathrm{p}<0.01,{ }^{* * *} \mathrm{p}<0.001 ;$ Standard errors are in parentheses.

In school-based systems, overall, we observe the same patterns as in work-based systems (Table 3). First, VET adults are clearly more likely to be "at-risk" or "weak" performers than the graduates of upper secondary education. In particular, VET adults are 3.1 (Ireland) to 14.7 (Belgium) times more likely to be "at-risk" 
performers than upper secondary graduates ${ }^{1}$; and the former are 1.9 (Ireland) to 5.2 (Belgium) times more likely to be "weak" performers than the latter. We observe, once again, between-country variation when comparing the problem-solving skills of VET adults to the skills of graduates from lower secondary education (or less). Except for Ireland, Norway and the Netherlands, VET adults have a higher likelihood of being "weak" performers - ranging 1.3 (Finland) to 2.0 (Belgium). In the Netherlands, on the contrary, lower secondary graduates are 1.5 times more likely than VET adults to be "weak" performers. In Ireland and Norway, the differences are not statistically significant $(\alpha=0.05)$. Estimating the likelihood of being an "at-risk" performer reveals an interesting picture as well. In fact, in Finland and Norway, VET adults have the same likelihood as lower secondary graduates to be "at-risk" performers. In Belgium and Poland, VET adults are more likely to be "at-risk" performers, and finally, in Ireland and the Netherlands, VET adults are less likely to achieve an "at-risk" problem-solving level.

1 Notice that the figures of Belgium (Flanders) are potentially overestimated. In fact, many observations in the Belgian data are classified as "not stated or inferred" on the vocational education and training variable. This is due to the fact certain ISCEDcategories, and more precisely the ISCED 3 (without distinction $\mathrm{A}-\mathrm{B}-\mathrm{C}$ ) and ISCED 4, could not be uniquely identified as being vocationally oriented or not. As a consequence, these have been coded as "not stated or inferred". 
Table 3: Likelihood of problem-solving skills proficiency in TREs by educational background in school-based countries (parameter estimates with standard errors and odds ratios)

\begin{tabular}{|c|c|c|c|c|c|c|c|}
\hline & & \multicolumn{3}{|c|}{ At risk performers } & \multicolumn{3}{|c|}{ Weak performers } \\
\hline & & $\mathrm{b}$ & $\begin{array}{l}\text { Odds } \\
\text { ratio }\end{array}$ & $\begin{array}{l}\text { Inverse } \\
\text { Odds } \\
\text { ratio }\end{array}$ & $\mathrm{b}$ & $\begin{array}{l}\text { Odds } \\
\text { ratio }\end{array}$ & $\begin{array}{l}\text { Inverse } \\
\text { Odds } \\
\text { ratio }\end{array}$ \\
\hline \multirow[t]{3}{*}{ Belgium $^{a}$} & Intercept & $\begin{array}{l}0.70^{* * *} \\
(.169)\end{array}$ & & & $\begin{array}{l}1.04^{* * *} \\
(.153)\end{array}$ & & \\
\hline & Low Sec vs. VET & $\begin{array}{l}-0.43^{*} \\
(.209)\end{array}$ & 0.65 & 1.54 & $\begin{array}{l}-0.68^{* *} \\
(.221)\end{array}$ & 0.51 & 1.98 \\
\hline & Up Sec vs. VET & $\begin{array}{l}-2.69^{* * *} \\
(.197)\end{array}$ & 0.07 & 14.67 & $\begin{array}{l}-1.64^{* * *} \\
(.167)\end{array}$ & 0.19 & 5.15 \\
\hline \multirow[t]{3}{*}{ Finland } & Intercept & $\begin{array}{l}-0.42^{* * *} \\
(.095)\end{array}$ & & & $\begin{array}{l}0.28^{* * *} \\
(.069)\end{array}$ & & \\
\hline & Low Sec vs. VET & $\begin{array}{l}-0.27 \\
(.153)\end{array}$ & 0.76 & 1.31 & $\begin{array}{l}-0.29^{*} \\
(.141)\end{array}$ & 0.75 & 1.34 \\
\hline & Up Sec vs. VET & $\begin{array}{l}-1.80^{* * *} \\
(.129)\end{array}$ & 0.16 & 6.06 & $\begin{array}{l}-1.06^{* * *} \\
(.080)\end{array}$ & 0.35 & 2.90 \\
\hline \multirow[t]{3}{*}{ Ireland } & Intercept & $\begin{array}{l}-0.25 \\
(.131)\end{array}$ & & & $\begin{array}{l}0.62^{* * *} \\
(.114)\end{array}$ & & \\
\hline & Low Sec vs. VET & $\begin{array}{l}1.04^{* * *} \\
(.218)\end{array}$ & 2.82 & 0.35 & $\begin{array}{l}0.06 \\
(.204)\end{array}$ & 1.06 & 0.95 \\
\hline & Up Sec vs. VET & $\begin{array}{l}-1.13^{* * *} \\
(.138)\end{array}$ & 0.32 & 3.09 & $\begin{array}{l}-0.67^{* * *} \\
(.125)\end{array}$ & 0.51 & 1.94 \\
\hline \multirow[t]{3}{*}{ Netherlands } & Intercept & $\begin{array}{l}-0.96^{* * *} \\
(.109)\end{array}$ & & & $\begin{array}{l}0.14 \\
(.087)\end{array}$ & & \\
\hline & Low Sec vs. VET & $\begin{array}{l}1.02^{* * *} \\
(.141)\end{array}$ & 2.78 & 0.36 & $\begin{array}{l}0.42^{* * *} \\
(.113)\end{array}$ & 1.52 & 0.66 \\
\hline & Up Sec vs. VET & $\begin{array}{l}-1.46^{* * *} \\
(.152)\end{array}$ & 0.23 & 4.32 & $\begin{array}{l}-1.01^{* * *} \\
(.110)\end{array}$ & 0.36 & 2.74 \\
\hline \multirow[t]{3}{*}{ Norway } & Intercept & $\begin{array}{l}-0.58^{* * *} \\
(.100)\end{array}$ & & & $\begin{array}{l}0.28^{* * *} \\
(.073)\end{array}$ & & \\
\hline & Low Sec vs. VET & $\begin{array}{l}0.26 \\
(.155)\end{array}$ & 1.29 & 0.77 & $\begin{array}{l}-0.06 \\
(.126)\end{array}$ & 0.95 & 1.06 \\
\hline & Up Sec vs. VET & $\begin{array}{l}-1.63^{* * *} \\
(.135)\end{array}$ & 0.20 & 5.11 & $\begin{array}{l}-0.96^{* * *} \\
(.092)\end{array}$ & 0.38 & 2.61 \\
\hline \multirow[t]{3}{*}{ Poland } & Intercept & $\begin{array}{l}0.52^{* * *} \\
(.121)\end{array}$ & & & $\begin{array}{l}0.53^{* * *} \\
(.111)\end{array}$ & & \\
\hline & Low Sec vs. VET & $\begin{array}{l}-1.32^{* * *} \\
(.197)\end{array}$ & 0.27 & 3.76 & $\begin{array}{l}-0.62^{* *} \\
(.177)\end{array}$ & 0.54 & 1.86 \\
\hline & Up Sec vs. VET & $\begin{array}{l}-1.60^{* * *} \\
(.125)\end{array}$ & 0.20 & 4.93 & $\begin{array}{l}-0.78^{* * *} \\
(.128)\end{array}$ & 0.46 & 2.18 \\
\hline
\end{tabular}

Note. ${ }^{*} \mathrm{p}<0.05,{ }^{* *} \mathrm{p}<0.01,{ }^{* * *} \mathrm{p}<0.001 ;$ Standard errors are in parentheses; ${ }^{\mathrm{a}}$ The Belgian estimates might be biased (see footnote 1). 


\section{Discussion and Conclusions}

The PIAAC data comprise the most comprehensive source of information on adults' skills to date. Therefore, it is now possible to investigate adults' problemsolving skills in TREs in a novel way. The present study focuses on gaining more in-depth insight into the problem-solving skills in TREs of European adults with a VET background. At a general level, when examining the similarities and differences in VET adults' problem-solving skills in TREs across 11 European countries, two main trends can be observed. First, our results show that only a minority of VET adults perform at a high level. Across all European countries in our study, adults with VET perform lower on average than adults with other educational backgrounds. Second, although adults with VET achieve a lower skill level throughout all countries, there seems to be substantial variation between countries with respect to the proportion of VET adults that can be identified as "atrisk" or "weak" performers.

As problem-solving skills in TREs are becoming increasingly important in work life (Goos, 2013), our findings are in line with the critical notion that there seems to be a gap between what is learned in VET and what is required at European workplaces (Baartman and de Bruijn, 2011). Currently, European countries are developing their VET systems to better meet the emerging needs of European workplaces, and different trends can be observed. Namely, in 6 (Ireland, Finland, Norway, Netherland, Austria and Germany) of 11 countries investigated in this study, the share of workplace learning is increasing, while in 5 countries (Belgium, Poland, Czech Republic, Slovak Republic and Denmark), this share is decreasing (cf. European Commission, 2013; Eurydice Highlights 2012/2013; OECD, 2009). A clear pattern with regard to the association between educational background and problem-solving skills, typical for the work- or school-based vocational education systems, does not emerge from our analysis. Instead, our findings indicate the variations that can be used as a starting point to identify beneficial VET approaches.

Our results suggest that when comparing adults with upper secondary education or higher with adults with a VET background, the same trend can be observed in all countries: VET adults are more likely to be at-risk or weak performers. However, when comparing VET adults with adults with lower secondary education or lower, three clusters of countries can be identified. In the first cluster, VET adults are more likely to be at-risk or weak performers than adults with lower secondary education or lower. This first cluster includes Finland, Czech Republic, Belgium, Poland and Slovak Republic, although for the latter this was only found for the likelihood of being an at-risk performer and for the former only for the likelihood of being a weak performer. In the second cluster, the reverse is true, namely VET adults perform better. This second cluster includes the Netherlands, Austria and Ireland, although for the latter two this was only observed for the at-risk performers. In the third cluster, containing Denmark, Germany and Norway, there is no difference between the level of TRE problem-solving skills of adults with VET background and lower secondary education backgrounds. These European variations hint towards influential differences between the countries. Namely, as VET is mediated by structural elements, such as the resources, norms, curriculum guidelines and externally mandated policies, future investigations need to focus on the constituent components of successful VET approaches within and across these three clusters of countries. 
Workplaces and vocational schools are the two main components of VET (Schaap, Baartman and de Bruijn, 2012). When considering the findings of this study, as a whole it is important to consider that grouping national VET systems based on the Cedefop calculations of Eurostat data may lead to over-simplification in understanding the problem-solving skills in TREs of European adults with a VET background (as there are large between and within country variations of VET). Therefore, to develop VET systems that can better meet the needs of future workplaces, additional studies are needed to more clearly understand the combination of school-based and workplace learning experiences (see also Gessler, 2009). Recently, Billett (2014) argued that the emerging challenges of VET research involve integrating learners' experiences in practice settings (i.e. workplaces) into educational programs. In the future, in addition to large-scale evaluations of VET adults' problem-solving skills in technology-rich environments, it will be necessary to gain additional knowledge on successful problem-solving processes in TRE, e.g. how learners are able to build meaningful and adaptive problem-solving skills in workplaces and vocational schools (Billett, 2014). Therefore, future research needs to focus on the in-depth analysis of problemsolving processes in TREs. In this respect, it could be beneficial to select the adults with a VET background from high-performing countries (e.g. Austria and the Netherlands) and the low-performing countries (e.g. Poland and Belgium) to understand why and where variations as well as low levels of problem-solving skills (cf. not classified group) exist in VET adults.

European countries are all facing a significant challenge in identifying approaches to enhance problem-solving skills for adults with a VET background. In the future, new technologies may be one way to support these higher TRE problem-solving skills. Recent studies have indicated that technology plays an increasingly important role in enabling flexible and adaptive life-long learning approaches. In practice, the role of technology is often to allow new learning experiences, for example, to learn problem-solving through game-based applications (Hämäläinen and De Wever, 2013), or to empower VET adults' professional development (Boldrini and Cattaneo, 2012; Motta, Boldrini and Cattaneo, 2013). Furthermore, studies have indicated that VET technologies have many benefits for the development of vocational specific skills (Cuendet and Dillenbourg, 2013; Minnaert, Boekaerts, De Brabander and Opdenakker, 2011). Finally, recent research findings support the potential of designing new technologies and applying existing technologies in workplace settings to enhance problem-solving in TREs (Tynjälä, Häkkinen and Hämäläinen 2014). 


\section{References}

Baartman, L. K. J., \& De Bruijn, E. (2011). Integrating knowledge, skills and attitudes: Conceptualizing learning processes towards vocational competence. Educational Research Review, 6, 125-134.

Billett, S. (2014). Integrating learning experiences across tertiary education and practice settings: A socio-personal account. Educational Research Review, 12, $1-13$.

Billett, S. (2008). Learning throughout working life: A relational interdependence between social and individual agency. British Journal of Education Studies, 55(1), 39-58.

Boldrini, E., \& Cattaneo, A. (2012). Collaborative writing on professional experiences as a means for fostering reflective thinking in VET curricula. In C. Gelati, B. Arfé \& L. Mason (Eds.), Issues in writing Research (pp. 180-188). Padova: Cleup.

Cuendet, S. \& Dillenbourg, P. (2013). The benefits and limitations of distributing a tangible interface in a classroom. In N. Rummel, M. Kapur, M. Nathan, S. Puntambekar (Eds.), To see the world and a grain of sand: Learning across levels of space, time and scale. CSCL2013 conference proceedings. Volume I (pp. 137-144). International Society of the Learning Sciences.

Eurydice Highlights. 2012/2013. The structure of the European education systems 2012/13: schematic diagrams:

http://eacea.ec.europa.eu/education/eurydice/index_en.php.

European Commission (2013): Work-based learning in Europe - Practices and Policy Pointers:

http://ec.europa.eu/education/lifelong-learning-policy/doc/work-based-

learning-in-europe_en.pdf. accessed: 18.05.2014.

Frey, C. \& Osborne, M. (2013). The future of employment: how susceptible are jobs to computerisation? Retrieved January 15, 2014: http://www.oxfordmartin.ox.ac.uk/downloads/academic/The_Future_of_Empl oyment.pdf.

Fuller, A., \& Unwin, L. (2004). 'Expansive Learning Environments: integrating personal and organisational development', in H. Rainbird, A. Fuller and A. Munro, Eds., Workplace Learning in Context (pp. 126-144), London: Routledge.

Gessler, M. (2009). Situational Learning and Cognitive Apprenticeship. In: R. MacLean, D. Wilson \& C. Chinien (Eds.), International Handbook of Education for the Changing World of Work. Bridging Academic and Vocational Learning (pp. 1611-1625). Berlin: Springer.

Goos, M. (2013). How the world of work is changing: A review of the evidence. ILO Research Paper, Retrieved April 11, 2014 from http://www.econ.kuleuven.be/public/n06022/ILO-20131205.pdf.

Hämäläinen, R., De Wever, B., Malin, A. \& Cincinnato, S. (2014). Using large scale PIAAC assessment data to empower professional development: Problem-solving in the context of technology-rich environments. Paper present in Earli sig 1 Conference: Assessment and evaluation. 27.-29. August, Madrid, Spain.

Hämäläinen, R. \& De Wever, B. (2013). Vocational education approach: New TEL settings - new prospects for teachers' instructional activities? International Journal of Computer-Supported Collaborative Learning. 8(3), 271-291. 
Lawn, M. (2013) Voyages of measurement in education in the Twentieth Century: experts, tools and centres, European Educational Research Journal, 12(1), 108-119.

Loveder, P. (2011). Globalization and vocational education and training, In Rubenson, K. (Ed.), Adult Learning and Education (pp. 283-287), Oxford, Academia Press.

Minnaert, A. M., Boekaerts, M., De Brabander, C., \& Opdenakker, M. C. (2011). Students' experiences of autonomy, competence, social relatedness, and interest within a CSCL environment in vocational education: The case of commerce and business administration. Vocations and Learning, 4(3), 175190.

Motta, E., Boldrini, E., \& Cattaneo, A. (2013). Technologies to "bridge the gap" among learning contexts in vocational training. In P. M. Pumilia-Gnarini, E. Favaron, E. Pacetti, J. Bishop \& L. Guerra (Eds.), Handbook of Research on Didactic Strategies and Technologies for Education: Incorporating Advancements (pp. 247-265). Hershey, PA: IGI Global.

OECD. (2009). Learning for jobs. OECD policy review of vocational education and training. Initial report. Paris: CERI.

OECD (2012). Literacy, Numeracy and Problem Solving in Technology-Rich Environments: Framework for the OECD Survey of Adult Skills. Paris: OECD Publishing. doi:10.1787/9789264128859-en.

OECD (2013a). OECD Skills Outlook 2013 First Results from the Survey of Adult Skills: http://skills.oecd.org/OECD_Skills_Outlook_2013.pdf. Accessed 1 August 2014.

OECD (2013b). Technical Report of the Survey of Adult Skills (PIAAC): http: http://www.oecd.org/site/piaac/_Technical\%20Report_17OCT13.pdf. Accessed 1 August 2014.

Shaap, H., Baartman, L., \& de Bruijn, E. (2012). Students' learning processes during school-based learning and workplace learning in vocational education: a review. Vocations and Learning, 5, 99-117.

Teichler, U. (2007). Does higher education matter? Lessons from a comparative graduate survey, European Journal of Education, 42(1), 11-34.

Tynjälä, P. (2013). Toward a 3-P model of workplace learning: a literature review. Vocations and Learning. Studies in Vocational and Professional Education, 6(1), 11-36.

Tynjälä, P., Häkkinen, P. \& Hämäläinen R., (2014, iFirst). TEL@work - towards integration of theory and practice. British Journal of Educational Technology. http://onlinelibrary.wiley.com/doi/10.1111/bjet.12164/pdf. 


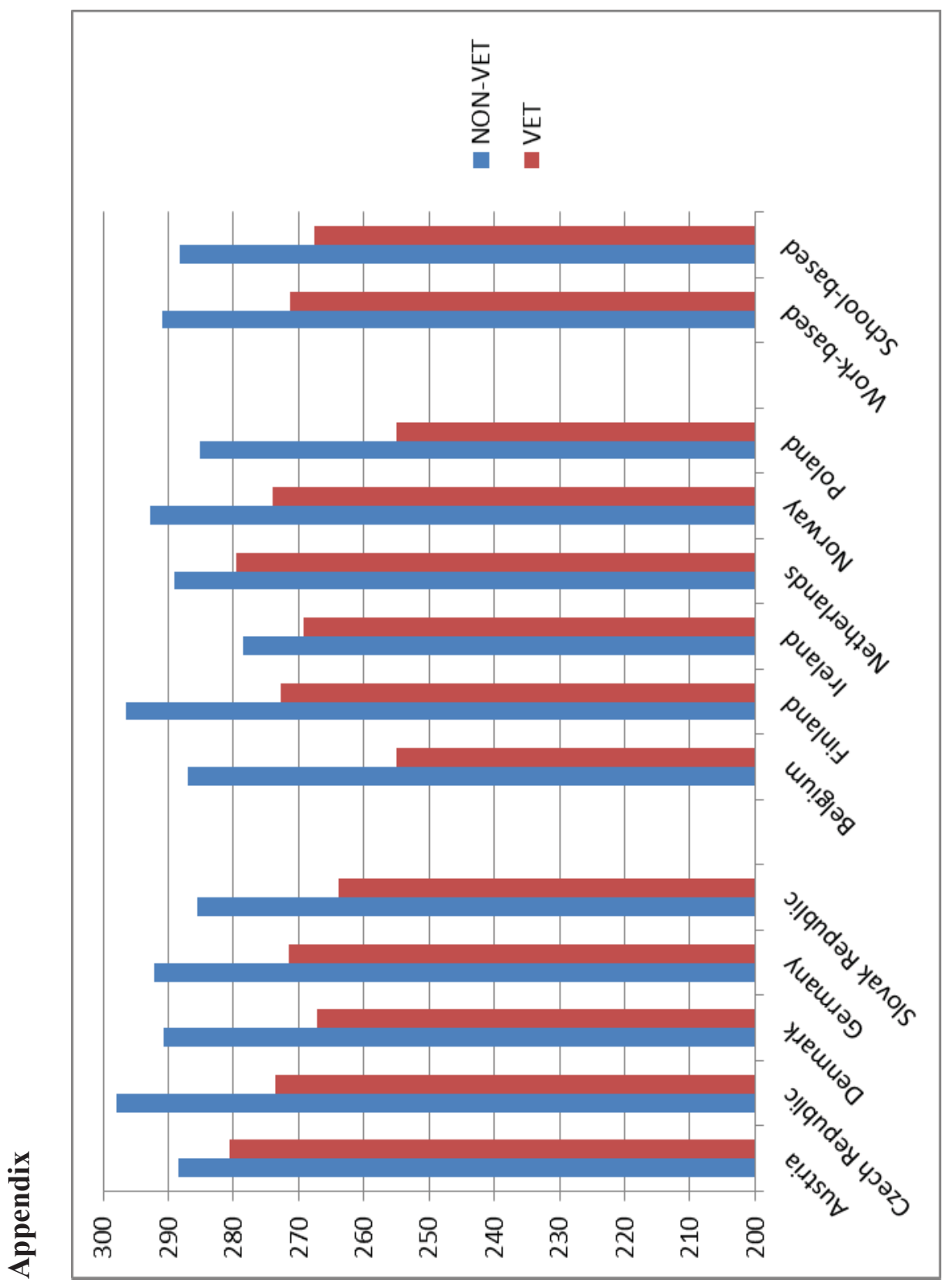




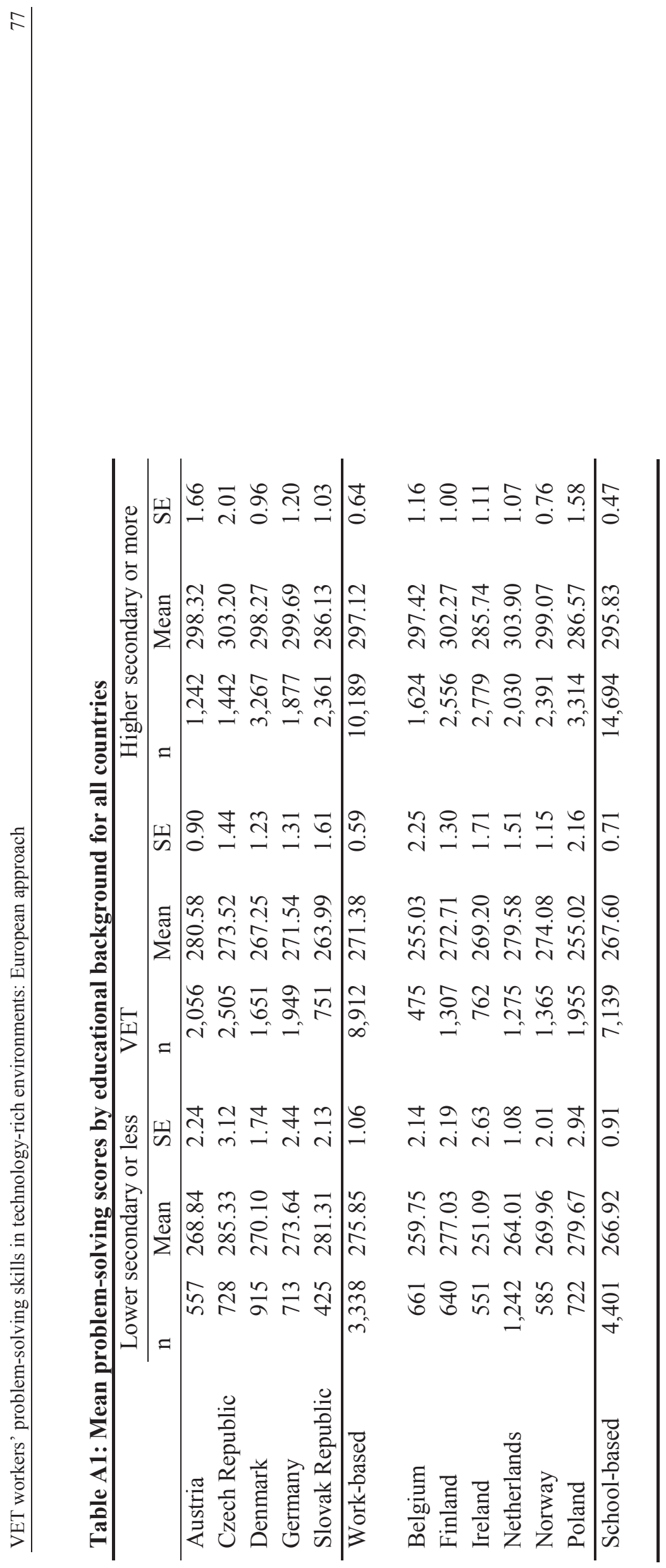




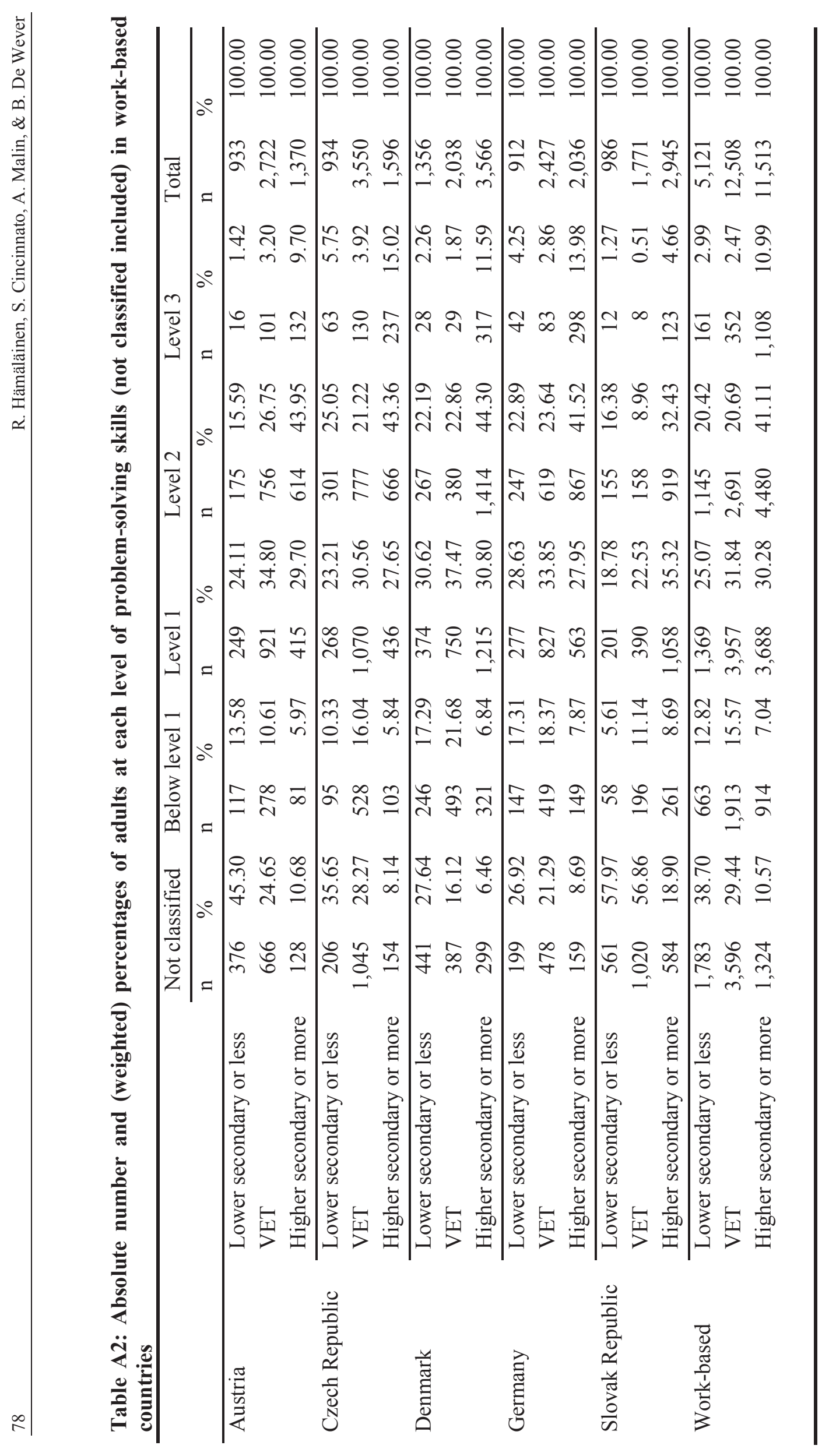




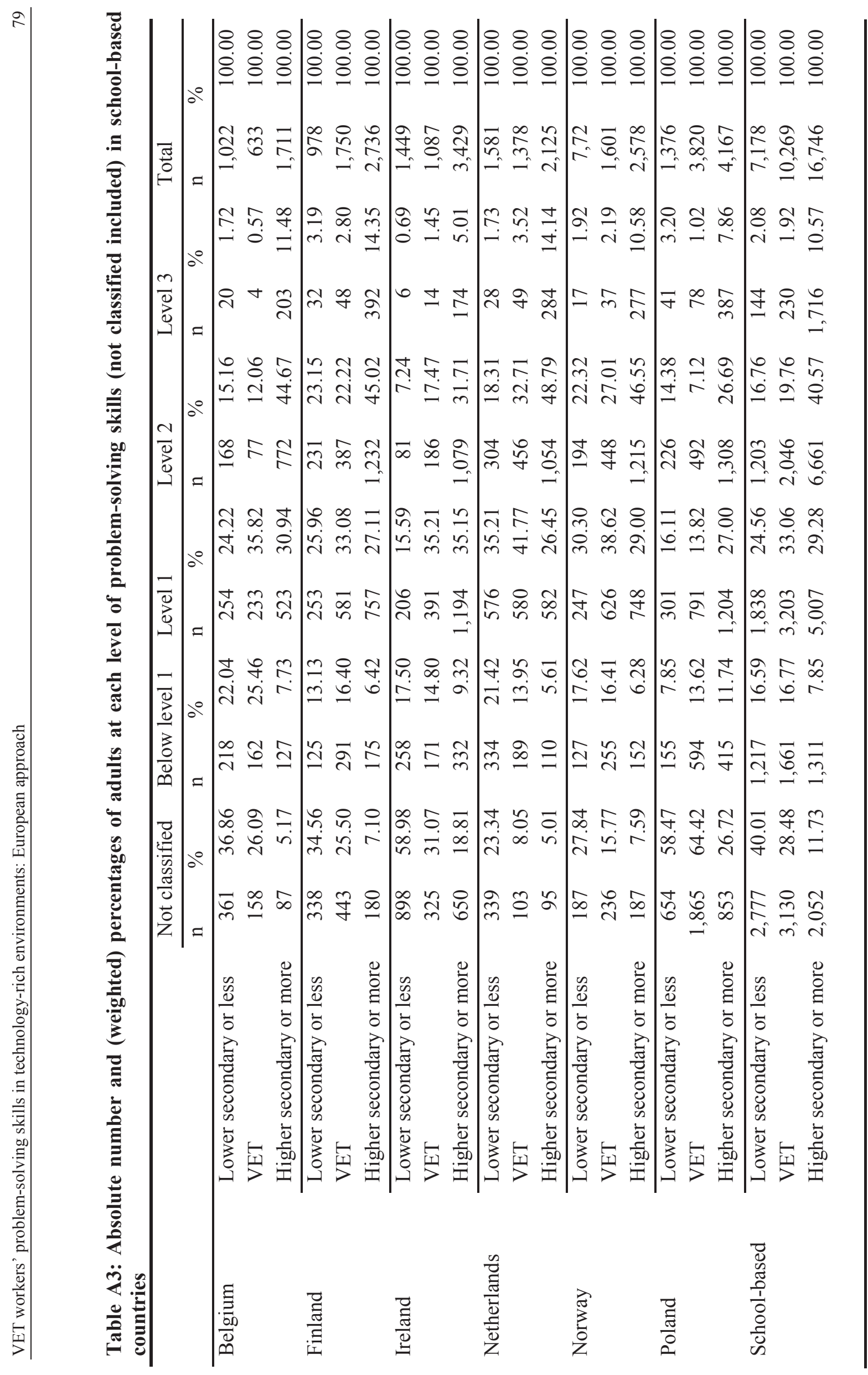


